\title{
The Importance of Supply Chain Management on Financial Optimization
}

\begin{abstract}
Arawati Agus ${ }^{1}$
Abstract: Many manufacturing companies are facing uncertainties and stiff competition both locally and globally, intensified by increasing needs for sophisticated and high value products from demanding customers. These companies are forced to improve the quality of their supply chain management decisions, products and reduce their manufacturing costs. With today's volatile and very challenging global market, many manufacturing companies have started to realize the importance of the proper managing of their supply chains. Supply chain management (SCM) involves practices such as strategic supplier partnership, customer focus, lean production, postpone concept and technology \& innovation. This study investigates the importance of SCM on financial optimization. The study measures production or SCM managers' perceptions regarding SCM and level of performances in their companies. The paper also specifically investigates whether supply chain performance acts as a mediating variable in the relationship between SCM and financial optimization. These associations were analyzed through statistical methods such as Pearson's correlation and a regression-based mediated analysis. The findings suggest that SCM has significant correlations with supply chain performance and financial optimization. In addition, the result of the regression-based mediated analysis demonstrates that supply chain performance mediates the linkage between SCM and financial optimization. The findings of the study provide a striking demonstration of the importance of SCM in enhancing the performances of Malaysian manufacturing companies. The result indicates that manufacturing companies should emphasize greater management support for SCM implementation and a greater degree of attention for production integration and information flow integration in the manufacturing system in order to maximize profit and minimize cost.
\end{abstract}

Keywords: Supply chain management, supply chain performance, financial optimization, mediating effect and regression based mediated analysis.

\section{Introduction}

The fierce competition in today's marketplace led by advances in technology, globalization, and information availability have forced many manufacturing companies to adopt supply chain management (Agus [3]). SCM has gained popularity as a significant system of operation in strategic planning and manufacturing process in order to achieve and sustain competitive advantage in the global market. With intense global competition and sophisticated needs of customers; manufacturers have been adopting innovative technologies and strategies to stay competitive (Lummus et al. [23]).

SCM encompasses the planning, managing and synchronizing the optimal flow of high-quality and value-for money products from the source the final customers (Wagner [30]). The systematic construction and efficient utilization of SCM is expected to be the most influential trend in shaping the system of operation in the future (Gundlach et al. [14]).

1, Graduate School of Business (UKM-GSB), Universiti Kebangsaan Malaysia, 43600, Bangi, Selangor Malaysia.

Email: araa@ukm.my
Therefore, most manufacturing companies realize that, SCM is increasingly crucial in contributing to the attainment of the goals, effectiveness and efficiency of the supply chain members and financial performance (Harwick [16], Tan [29]).

Increasing global competition and the rising costs of natural resources today as well as customers' demands for higher product quality, greater product selection and better customer service have created new challenges for manufacturing companies. The recent global business scenario has led many Malaysian manufacturing companies to adopt SCM in order to enhance supply chain stability as well as efficiency, and ultimately sustain the overall firm performance. Many researchers claim that supply chain management can result in better performance (Christopher [10], Christiansee and Kumar [9], Agus [3]), but very few empirical studies have been conducted to investigate the impact of SCM on supply chain performance and financial optimization in one study. In order to investigate the extent of the significance of SCM, the main objectives of this paper are: (a) To empirically determine whether SCM has significant impact on supply chain performance. (b) To empirically discover whether SCM has 
significant impact on financial optimization. (c) To empirically discover whether supply chain performance has a mediating effect on the linkage between SCM and financial optimization

This paper explores the possibility of adopting SCM as the basis for enhancing supply chain performance and financial optimization in Malaysian manufacturing companies. First, this paper proceeds with a brief explanation of the SCM principles; second, it discusses the validity and reliability test; third, it highlights the conceptual framework which includes the explanation of the conceptual model and hypotheses. Fourth, it discusses the methodology adopted. Finally, the overall results are then discussed and implications highlighted.

This final part also includes demonstrating the results of the preliminary statistical analyses which include Pearson's correlation and a regression-based mediated analysis between SCM, supply chain performance and financial optimization. It also includes confirming the initial result with the structural equation modelling (SEM).

\section{Methods}

\section{Supply Chain Management}

Various viewpoints have been held in the definition of SCM. Mentzer et al. [24] define SCM as a strategic coordination of the business functions and processes within a particular company and across businesses, for the purposes of improving the long-term performance of the individual companies and the supply chain as a whole. In addition, Svensson [28] argues that SCM is a management philosophy that addresses the overall dependencies of activities, SCM members, and resources on an operational, tactical, and strategic level, from the point of origin to the point of consumption. SCM involves the process of planning, implementing and controlling operation of the supply chain with the purpose of fulfilling the customers' needs. SCM also includes all movement and storage of raw material, WIP, and finished goods in the supply chain (Lambert et al. [19], Christopher [10], Christiansee and Kumar [9]).

SCM is a cross-functional approach which involves managing the movement of raw materials into an organization and the movement of finished goods to end consumer. SCM seeks to enhance performance by closely integrating and coordinating the internal operations within a company and effectively linking them with the external operations of suppliers and customers. Therefore, one of the purpose of SCM is to improve trust and collaboration among supply chain partners. However, manufacturing companies must achieve a relatively high degree of SCM integration which involves integration, coordination and collaboration across organizations and throughout the supply chain to achieve high financial optimization (Stevens [27], Min and Mentzer [25]; Lambert et al. [19], Christopher [10]; Christiansee and Kumar [9], Agus [3]; Wagner [30]). Gunasekaran et al. [13] propose a framework for supply chain performance measurement. In addition, several researchers have suggested that SCM is closely linked to the enhanced performance (Carter and Narasimhan [8], Kuei et al. [18]).

\section{Independent and Dependent Variables' Mea- surements: Validity and Reliability Test}

In this study, SCM measurements represent a manager's assessment of the overall level of the SCM process in the company. Validity and reliability tests were used to select and assess the final items of the independent constructs that are used for statistical testing. The critical variables of SCM (which includes strategic supplier partnership, customer focus, lean production, postpone concept and technology and innovation) in this study had content validity because an extensive review of the literature was conducted in selecting the measurement items and the critical constructs; and all the items and factors have been evaluated and validated by professionals in the area of operation management/ SCM. In addition, the draft questionnaire was pretested with academics and practitioners to check its content validity and terminology and it was modified or revised accordingly (Frohlich and Westbrook [12]). Since data for this study was generated using a multi-scaled responses, it was deemed necessary to test for reliability. The reliability analysis was conducted by computing the Cronbach's alpha for the main constructs. All the Cronbach's alpha measures for the main constructs exceed the threshold point of 0.70 suggested by Nunnally [26].

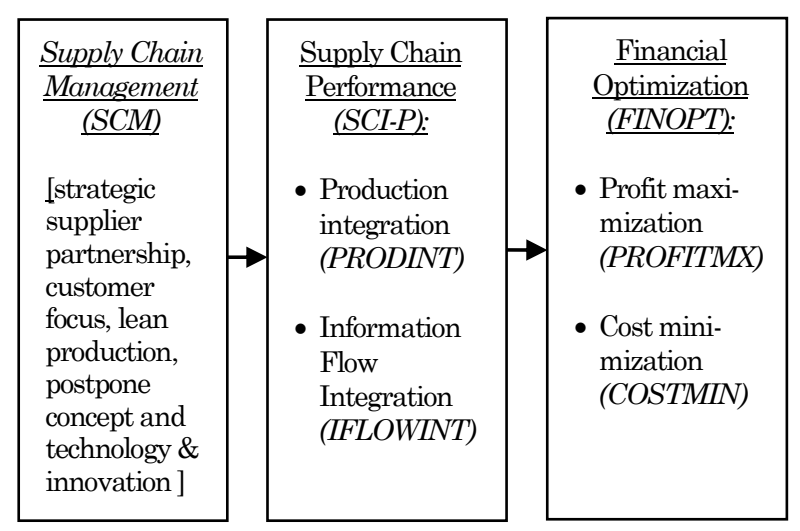

Figure 1. The conceptual model showing the relationships between SCM, supply chain performance and financial optimization. 


\section{The Conceptual Framework and Hypotheses The Conceptual Model}

This paper explores the relationships between SCM, supply chain performance and financial optimization within the context of the Malaysian manufacturing industry. The proposed conceptual model, as depicted in Figure 1, is based on three main constructs investigated in this study namely: (i) Supply chain management (SCM); (ii) supply chain performance (SCI-P); and (iii) financial optimization (FINOPT).

The SCM is derived from the mean of several SCM practices such as strategic supplier partnership, customer focus, lean production, postpone concept and technology and innovation. Strategic supplier partnership involves developing trust and collaboration among supply chain partners. Lean production is associated with elimination all non-value adding activities and waste reduction within an organization. Customer focus is the emphasis placed by companies in meeting the unlimited expectations of its customers. Postponement involves the process of delaying final product configuration until the actual order requirement is specified by the customer. New technology and innovation refers to the application of the latest scientific or engineering discoveries to the design of operations and production processes in SCM (Agus [3], Li et al., 2006 [21], ,Womack and Jones [31]).

On the other hand, SCI-P is manifested by production integration and information integration. In addition to operationalize financial optimization, two elements are identified which include profit maximization and cost minimization. The hypothesized model in the present study demonstrates that SCM is important in enhancing performance and it is the duty of managers to utilize and make the best use of them. The conceptualization of the model aims at understanding the significance of SCM on financial optimization in a better way (Agus, [3]).

\section{Hypotheses}

The goal of SCM is specified as adding value for customers at reduced overall costs (Lummus et al. [22]). SCM involves practices like strategic supplier partnership, customer focus, lean production, postpone concept and technology and innovation. The value added should first be reflected in supply chain performance such as in the form of improvement in production integration and information flow integration that might arise from effective SCM implementation. Based on the theoretical justification and supporting empirical evidence (Kuei et al. [18], Lummus et al. [22], Tan [29]), the first hypothesis proposes that SCM has a positive influence on supply chain performance. Logically, it makes sense that with proper implementation and adoption of SCM, production integration and information flow integration well as the overall supply chain performance would be enhanced. With effective implementation of SCM practices such as strategic supplier partnership, cooperation and exchange of information would be enhanced. As a result, the production can be synchronized and integration of information flow can be improved.

The second hypothesis suggests that SCM has a positive impact on financial optimization. Bowersox et al. [7] suggest in their study that high SCM implementers exhibit significantly higher scores for performance. They also investigate how supply chain competency leads to business success. For instance, the main principle of lean production in SCM is waste reduction. Effective implementation of lean would reduce waste in the forms of motion, transportation and inventory waste and ultimately lead to the overall cost minimization and profit maximization.

The third research proposition suggests that improved supply chain performance would ultimately have a positive effect on financial optimization. Justification for the hypothesis is based on the rationale that supply chain performance evaluation is closely linked to the enhanced financial performance (Carter and Narasimhan [8]; Kuei et al. [18]). The fourth and fifth hypotheses are the main concern of this paper which propose that supply chain performance mediates the linkage between SCM and the two financial optimization variables. Hence in short, this study tests the following main research hypotheses:

$H_{1}$ : SCM is positively related to supply chain performance.

$H_{2}$ : SCM is positively related to financial optimization.

$H_{3}$ : Supply chain performance has a positive relationship with financial optimization.

$H_{4}$ : Supply chain performance mediates the linkage between SCM and profit maximization.

$H_{5}$ : Supply chain performance mediates the linkage between SCM and cost minimization.

\section{Research Methodology}

This paper formed part of a larger study on SCM. The broader study had focused on individual constructs of SCM that led to collective influences on performances. The instrument used in this study was a structured survey questionnaire, which was 
designed to assess the manufacturing companies in term of the described dimensions. The instrument developed in this study was consisted of two major parts. The first part comprised several constructs and variables measuring SCM, and the second part held questions related to several performance measurements including supply chain performance and financial optimization.

The questions were designed using a seven point Likert scale such that $1=$ strongly disagree to $7=$ strongly agree. Several items of SCM, which had been widely referred, were extracted. Similarly, the dependent constructs namely supply chain performance and financial optimization also used a sevenpoint interval scale, representing a range of agreement on a statement whether over the past three years the level of performance was high relative to competitors after implementing SCM. In addition, several questions that sought general classification and demographic information on the company were posed.

The unit of analysis of this study was company level and each manufacturing company was represented (the respondent) by either production or SCM manager. The sampling frame was derived from the Federation of Malaysian Manufacturers Directory (FMM). The companies included in the survey operated in a broad range of industries including the automotive, chemical, computer, construction, consumer products, electronics, industrial products, medical device, packaging, pharmaceutical, paperboard, semiconductor, and telecommunications industries. Two hundred and fifty responses were received and analyzed.

The primary purpose of the study was to measure managers' perceptions of the level of implementations of the SCM and also to gain insight into the benefits of implementing SCM in the manufacturing industry. The goal was to understand and determine measures of SCM that could enhance supply chain performance and financial optimization. Face to face interviews with the managers were carried out to ensure the information accuracy, validating the outcome of the analysis and developing an understanding of the practical aspects of SCM principles and implementations. In investigating the influence of SCM on supply chain performance and financial optimization, the a regression-based mediated analysis was utilized to evaluate and analyze the magnitude and direction of the linkages between these constructs. The regression-based mediated analysis was used in testing the hypothesis instead of SEM because the latter method required large sample size for the model to be stable for the inferences purposes.

\section{Results and Discussion}

\section{Correlations Analyses}

As a preliminary analysis, Pearson's correlation analysis was conducted to establish associations between the SCM and supply chain performance as well as financial optimization. Table 1 exhibited correlations between SCM, supply chain performance, profit maximization and cost minimization. The SCM is derived from the mean of several SCM practices such as strategic supplier partnership, customer focus, lean production, postpone concept and technology and innovation. SCI-P is being represented by the mean of production integration and information flow integration. The result indicated that SCM had significant correlations with supply chain performance $(\mathrm{r}=.702)$, profit maximizetion $(r=.592)$ and cost minimization $(r=.621)$.

The Mediating Effect of Supply Chain Performance in the Linkage between SCM and Financial Optimization: The Regression-Based Mediated Analysis

Having found that there were significant correlations between SCM and supply chain performance as well as financial optimization, the question was then directed at examining whether supply chain performance mediated the relationship between SCM and financial optimization. A regression based mediated analysis was conducted for this purpose. Before the regression analysis was initiated, a multicollinearity test was conducted and the result did not indicate any multicollinerity problem since all VIF values were lower than 5 or have a tolerance value of 0.10 (Hair et al. [15]; Agus[1]).

Baron and Kenny [5] and Judd and Kenny [17] have discussed several steps establishing mediation. In testing the mediating effects, the SCM scales were substituted by a single variable, obtained from the mean of several SCM scores (see Figure 1). Specifically, as described above, Table 2 (Step 1)

Table 1. Pearson's Correlation between SCM, supply chain performance, profit maximization and cost minimization

\begin{tabular}{lcccc}
\hline Variables & SCM & SCI-P & $\begin{array}{c}\text { Profit } \\
\max \end{array}$ & $\begin{array}{c}\text { Cost } \\
\text { min }\end{array}$ \\
\hline SCM & 1 & & & \\
SCI-P & $.702^{* *}$ & 1 & & \\
Profit max & $.592^{* *}$ & $.542^{* *}$ & 1 & \\
Cost min & $.621^{* *}$ & $.562^{* *}$ & $.656^{* *}$ & 1 \\
\hline
\end{tabular}

Note: $\dagger$ if $\mathrm{p}<0.10$, * if $\mathrm{p}<0.05$; ** if $\mathrm{p}<0.01 ; * * *$ if $\mathrm{p}<$ 0.001 All correlations are two-tailed. 
revealed significant linkages between SCM and profit maximization $(\mathrm{b}=0.592$, ) as well as cost minimization $(b=0.621)$. Step 2 showed positive linkages between two supply chain performances and both financial optimization measures (profit maximization and cost minimization). Finally, Step 3 indicated that when the two supply chain performances were controlled in a simultaneous regression, the relationship between SCM and profit maximization was still significant but subsided $(\mathrm{b}=$ 0.343).

On the other hand, the relationship between SCM and cost minimization became lesser with the inclusion of the two supply chain performances but still indicated significant value $(\mathrm{b}=.363)$, as shown in Table 2. According to Baron and Kenny [5], for the mediating effect to exist, the beta coefficients of the independent variable (SCM) in Model 3 should be lesser than in the Model 1 with the inclusion of the mediating variable.

Taken together, these results suggested that SCM affected profit maximization and cost minimization through production integration and information flow integration, hence offering support for Hypotheses 4 and 5. The results indicated that the beta coefficients of SCM with the inclusion of supply chain performance in Step 3 had lower values than in Step 1 (see Table 2) in both examples. Since the values of the beta coefficients in Step 3 were lower than the value of the beta coefficients of the inde pendent variable in Step 1 when regressed on the two financial optimization measures (profit minimization

Table 2. The mediating effect of supply chain performance on the linkage between SCM and financial optimization.

\begin{tabular}{ccccccc}
\hline & \multicolumn{4}{c}{ Financial Optimization } \\
\cline { 2 - 7 } & \multicolumn{3}{c}{$\begin{array}{c}\text { Profit } \\
\text { Maximization }\end{array}$} & \multicolumn{3}{c}{$\begin{array}{c}\text { Cost } \\
\text { Minimization } \\
\text { (Dependent variable) }\end{array}$} \\
\cline { 2 - 7 } & $\begin{array}{c}\text { Step1 } \\
\text { (S1) }\end{array}$ & $\begin{array}{c}\text { Step2 } \\
\text { (S2) }\end{array}$ & $\begin{array}{c}\text { Step3 } \\
\text { (S3) }\end{array}$ & $\begin{array}{c}\text { Step1 } \\
\text { (S1) }\end{array}$ & $\begin{array}{c}\text { Step2 } \\
\text { (S2) }\end{array}$ & $\begin{array}{c}\text { Step3 } \\
\text { (S3) }\end{array}$ \\
\hline SCM & .592 & & .343 & .621 & & .363 \\
& $* * *$ & & $* * *$ & $* * * *$ & & $* * *$ \\
PRODINT & & .270 & .137 & & .232 & .092 \\
& & $* * *$ & $*$ & & $* * *$ & $*$ \\
IFLOWINT & & .406 & .253 & & .473 & .312 \\
& & $* * *$ & $* *$ & & $* * * *$ & $* *$ \\
R Square & .350 & .352 & .408 & .386 & .408 & .454 \\
F & 133.8 & 67.08 & 56.46 & 155.6 & 65.4 & 68.2 \\
& $* * *$ & $* * * *$ & $* * *$ & $* * *$ & $* * *$ & $* * * *$ \\
$\Delta$ R Square & & .002 &. $\mathbf{0 5 8}$ & & 0.022 &. $\mathbf{0 6 8}$ \\
& & & $(\mathrm{S} 3-1)$ & & & $(\mathrm{S} 3-1)$ \\
& & & .056 & & &. $\mathbf{0 4 6}$ \\
& & & $(\mathrm{S} 3-2)$ & & & $(\mathrm{S} 3-2)$ \\
\hline
\end{tabular}

Note: $\mathrm{N}=250$. The coefficients are standardized $B$ weights. Note: $\dagger$ if $p<0.10, *$ if $p<0.05 ; * *$ if $p<0.01 ;{ }^{* * *}$ if $p<0.001$

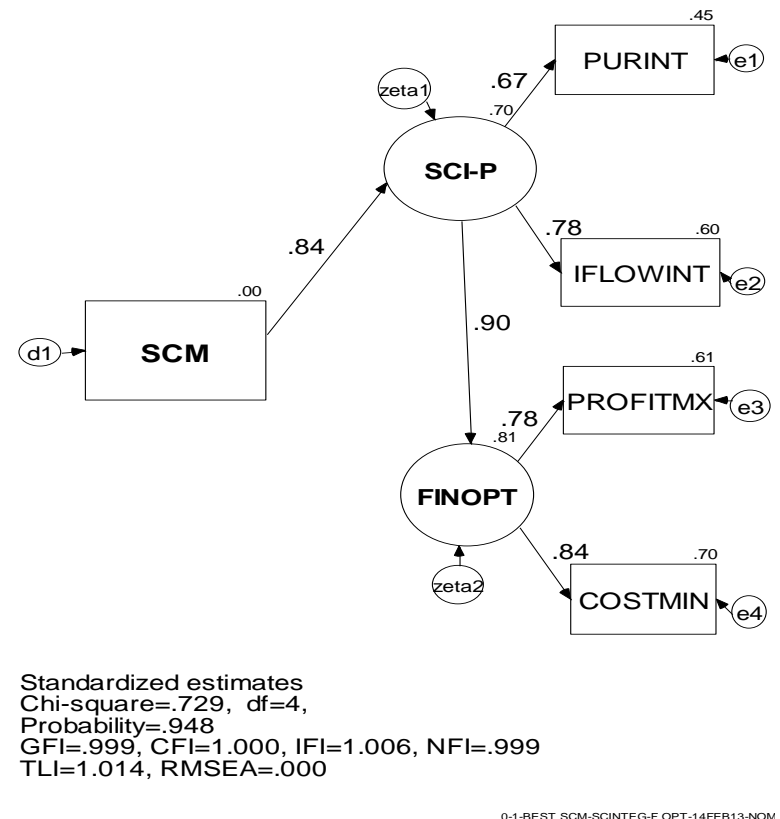

Figure 2. The structural equation model showing the linkages between SCM, supply chain performance and financial optimization.

and cost minimization) but were still significant, the result suggested that in general, supply chain performance had mediating effect on the linkage between SCM and financial optimization.

\section{Structural Equation Modeling (SEM)}

In addition, the author also performed a structural equation modeling (SEM) analysis to further support the proposition that supply chain performance mediated the linkage between SCM and financial optimization $\left(\mathrm{H}_{4}\right.$ and $\left.\mathrm{H}_{5}\right)$. In testing the mediating effects, the SCM scales were substituted by a single variable, obtained from the mean of several SCM scores. Meanwhile the latent mediating construct, 'supply chain performance' was operationalized by two manifest variables, production integration and information flow integration. Lastly, the latent endogenous construct 'financial optimization' was represented by profit maximization and cost minimization.

The SEM result indicated that the Chi-square value was 0.729 with a probability value of 0.948 (Figure 2). This suggested that the model had a good fit. The probability value was considerably sufficient ( $p$-value $>0.05$ ) in supporting the proposition that the overall model fitted the data. In addition, other statistical structural indices such as Goodness of fit index (GFI $=0.999)$, Bentler comparative fit index $(\mathrm{CFI}=1.00)$, Normed fit index (NFI = 0.999) and RMSEA (0.000) further suggested that the model had a satisfactory fit. Since the probability value and structural modeling indices were well above the recommended 
level, the model was considered to be a reasonable representation of the data (Hair et al. [15]; Agus [2], Agus and Hajinoor [4]).

The main findings indicated that the direct structural effect of SCM on supply chain performance was high (structural effect $=0.84$ ) and this linkage was associated with a low standard error (0.061) and a non-zero critical ratio (11.272). The direct structural effect of supply chain performance on financial optimization was relatively higher (structural effect $=0.90$ ) and was also significant with a low standard error (0.100) and a non-zero critical ratio (9.489). The finding indicated that the structural effects between these constructs were positive and significant.

\section{Conclusion}

SCM provides a vision that focuses everyone in an organization on product, production and quality improvements. SCM refers to how firms utilize their suppliers' processes, technologies, and capabilities to enhance competitive advantage (Farley [11]), and how the manufacturing, logistics, materials, distribution and transportation functions are integrated within organizations (Lee and Billington [20]). SCM not only can drive performance, but also allow companies to serve their customers better in turbulent market conditions. The implementation of SCM has never been more crucial to the survival of a manufacturing company now than before.

The results also highlight the fact that supply chain management has a positive relationship with supply chain performance and financial optimization. In addition, the result of the regression-based mediated analysis demonstrates that supply chain performance mediates the linkage between SCM and financial optimization. This association is also highlighted by utilizing SEM. The results of the study assist in the understandings of how SCM influences supply chain performance and financial optimization.

In short, the findings of this study suggest that SCM would be able to support and enhance the supply chain performance as well as increase the level of financial optimization. The manufacturing company would have the ability to coordinate or integrate production and information flow which are very crucial to fulfill the customer requirements and customization. This subsequently would lead to better financial optimization. The positive relationships between SCM, supply chain performance and financial optimization was significant for two reasons. First, it highlights the need to effectively implement SCM and identify obstacles towards the implementations.
Second, combined with the significance of implementing SCM, it demonstrates the importance of creating production and information integration within the supply chain aggressively. In an intensely competitive environment, maintaining and improving supply chain integration and flexibility to better anticipate market needs and to improve performance are pertinent to the survival of the business. The importance of an effective SCM is further illustrated by the fact that enhancing supply chain performance has a greater impact on financial optimization.

The conclusion emerging from this study is that SCM would ultimately result in positive gains. By strengthening SCM practices, the cost of production could be minimized and consequently lead to profit maximization. The result indicates that manufacturing companies should emphasize a greater support to SCM and a greater degree of management attention towards production integration and information flow integration in the manufacturing system in order to optimize financial performance.

\section{Acknowledgment}

The author would like to thank the Graduate School of Business, Universiti Kebangsaan Malaysia (UKM-GSB) for providing a conducive environment for lecturers and students to conduct their research. The study is conducted under UKM research grant UKM-GUP-EP-07-18-116.

\section{References}

1. Agus, A., Reducing the Effects of Multicollinearity through Principle Component Analysis: A Study on TQM Practices, Malaysian Management Review, 35(1), 2000, pp. 43-50.

2. Agus, A., A Linear Structural Modeling of Total Quality Management Practices in Manufacturing Companies in Malaysia. Total Quality Management, 12(5), 2001, pp. 561-573.

3. Agus, A., The Importance of Incorporating SCM In Supply Chain Management (SCM) Processes in Enhancing Performance, 16 th PBEAM 2008: Innovation for Sustainable Future Visions for 2020, QUT, Brisbane, Australia, July 2-4 2008 ISBN 978-1-74107-243-3

4. Agus, A., and Hajinoor, M. S., Lean Production Supply Chain Management as Driver Towards Enhancing Product Quality and Business Performance: Case Study of Manufacturing Companies in Malaysia, International Journal of Quality and Reliability Management, (Emerald), 29(1), 2012, pp. 92-121.

5. Baron, R. M., and Kenny, D. A., The ModeratorMediator Variable Distinction in Social Psycho- 
logical Research: Conceptual, Strategic and Statistical Considerations. Journal of Personality and Social Psychology, 51(1), 1986, pp. 11731182.

6. Bentler, P. M., Comparative Fit Indexes in Structural Models, Psychological Bulletin, 102(2), 1990, pp. 238-246.

7. Bowersox, D.J., Closs, D.J. and Keller, S.B., How Supply Chain Competency Leads to Business Success, Supply Chain Management Review, 4(4), 2000, pp. 70-78.

8. Carter, R. J., and Narasimhan, R., (1994). The Role of Purchasing and Materials Management in Total Quality Management and Customer Satisfaction, International Journal of Purchasing and Materials Management, 30 (3), 1994, pp. 313.

9. Christiansee, E., and Kumar, K., "ICT-Enabled Coordination of Dynamic Supply Webs, International Journal of Physical Distribution and Logistics Management, 30, (3/4), 2000, pp. 268285.

10. Christopher, M., Logistics and Supply Chain Management: Strategies for Reducing Cost and Improving Service, Financial Times: Pitman Publishing, 1998.

11. Farley, G.A., Discovering Supply Chain Management: A Roundtable Discussion, APICS - The Performance Advantage, 7(1), 1997, pp.38-9..

12. Frohlich, M. T., and Westbrook , R., Arcs of Integration: An International Study of Supply Chain Strategies, Journal of Operations Management, 19(1), 2001, pp.185-200.

13. Gunasekaran, A., Patel, A., and Mc Gaughey R. E., A Framework for Supply Chain Performance Measurement, International Journal of Production Economics, 87(3), 2003, pp. 333-347.

14. Gundlach, G.T., Bolumole, Y.A., Eltantawy, R.A. and Frankel, R., The Changing Landscape of Supply Chain Management, Marketing Channels of Distribution, Logistics and Purchasing, Journal of Business and Industrial Marketing, 21(7), 2006, pp. 428-438

15. Hair, J.F., Anderson, R.E., Tatham, R.L. and Black, W.C., Multivariate Data Analysis, Englewood Cliffs, NJ: Prentice-Hall, 1998.

16. Harwick, T. Optimal Decision-Making for the Supply Chain, APICS: The Performance Advantage, 7(1), 1997, pp. 42-44.

17. Judd, C. M., and Kenny, D. A., Process Analysis: Estimating Mediation in Treatment Evaluations. Evaluation Review, 5(1), 1981, pp. 602 619 .
18. Kuei, C.H., Madu, C.N., and Lin, C., The Relationship between Supply Chain Quality Management Practices and Organizational Performance. International Journal of Quality and Reliability Management, 18(8), 2001, pp. 864-872.

19. Lambert, D. M. Cooper, M. C., and Pagh, J. D., Supply Chain Management: Implementation Issues and Research Opportunities, International Journal of Logistics Management, 9(2), 1998, pp. 1-19.

20. Lee, H.L., Billington, C., Managing Supply Chain Inventory: Pitfalls and Opportunities, Sloan Management Review, 33(3), 1992, pp. 6573.

21. Li, S., Ragu-Nathan, B., Ragu-Nathan, T.S., and Rao, S.S., The Impact of Supply Chain Management Practices on Competitive Advantage and Organizational Performance, Omega, 34(2), 2006, pp. 107-124.

22. Lummus, R.R., Vokurka, R.J., and Alber, K.L., Strategic Supply Planning, Production and Inventory Management Journal, 39(3), 1998, pp. 49-58.

23. Lummus, R., Duclos, L., and Vokurka, R., Supply Chain Flexibility: Building a New Model, Global Journal of Flexible Systems Management, 4(4), 2003, pp.1-13.

24. Mentzer, J.T., DeWitt, W., Keebler, J.S., Min, S., Nix, N.W., Smith, C.D. and Zacharia, Z.G., Defining Supply Chain Management, Journal of Business Logistics, 22(2),2001, pp. 1-25.

25. Min, S. and Mentzer, J.T., The Role of Marketing in Supply Chain Management, International Journal of Physical Distribution \& Logistics Management, 30(9), 2000, pp. 765-87.

26. Nunnally, J. Psychometric Theory. New York: Mc Graw Hill, 1967.

27. Stevens, G., Integrating the Supply Chain, International Journal of Physical Distribution and Materials Management, 19(8), 1989, pp. 3-8.

28. Svensson, G., The Theoretical Foundation of Supply Chain Management: A Functionalist Theory of Marketing, International Journal of Physical Distribution and Logistics Management, 32(9), 2002, pp. 734-54.

29. Tan, K., Supply Chain Management: Practices, Concerns, and Performance Issues, Journal of Supply Chain Management, 38(1), 2002, pp. 42-53

30. Wagner, S.M., Intensity and Managerial Scope of Supplier Integration, Journal of Supply Chain Management, 39(4), 2003, pp. 4-13.

31. Womack, J. P., and Daniel, T. J., Lean Thinking, Free Press, pp. 352, 2003. 